\title{
Pengenalan Sistem Pertanian Hidroponik Rumah Tangga di Desa Dalung
}

\author{
Luh Putu Yulika Rara Gayatri' ${ }^{1}$, Luh Putu Mahyuni*2 \\ 1,2 Fakultas Ekonomi dan Bisnis, Universitas Pendidikan Nasional \\ *e-mail: yulikararagayatri24@gmail.com¹, mahyuniluhputu@undiknas.ac.id²
}

\begin{abstract}
Hydroponics is a farming technique that uses water and without using soil in the planting medium (soilless). The hydroponic farming system is an alternative that can be used to increase agricultural productivity, especially on narrow land. This community service activity is intended to introduce to the community, especially in Dalung Village about hydroponic agriculture. By introducing a hydroponic farming system, it is expected that it can increase agricultural yields on narrow land and accelerate harvesting. In this community service activity, the methods used are observation of problems, preparation of tools and materials, interviews, socialization through video campaigns, planting and maintenance. At the end of this community service activity, it is expected that the community will have sound knowledge about hydroponic farming systems and be able to apply hydroponic making at their respective homes even on a narrow land. The results of this community service are: (1) Increasing public knowledge about hydroponic agriculture by socializing through video campaigns, and (2) People knowing how to make hydroponics on a narrow land in Dalung Village. The conclusion of this community service activity is that through the introduction of the hydroponic farming system, the people of Dalung Village and other areas in Indonesia with narrow land can maximize the use of existing land for productive and economically valuable agriculture.
\end{abstract}

Keywords: Hydroponics, Narrow Land Farming, Productive Farming

\begin{abstract}
Abstrak
Hidroponik adalah teknik bercocok tanam yang menggunakan air dan tanpa memanfaatkan tanah dalam media tanamnya (soilless). Sistem pertanian hidroponik menjadi alternatif yang dapat dimanfaatkan untuk meningkatkan produktifitas pertanian terutama pada lahan yang sempit. Kegiatan pengabdian masyarakat ini ditujukan untuk mengenalkan kepada masyarakat khususnya di Desa Dalung mengenai pertanian hidroponik. Dengan memperkenalkan sistem pertanian hidroponik, diharapkan dapat meningkatkan hasil pertanian pada lahan sempit dan mempercepat panen. Dalam kegiatan pengabdian masyarakat ini metode yang digunakan yakni, observasi permasalahan, persiapan alat dan bahan, wawancara, sosialisasi melalui video campaign, penanaman dan pemeliharaan. Pada akhir kegiatan pengabdian masyarakat ini diharapkan masyarakat memiliki pengetahuan yang baik mengenai sistem pertanian hidroponik serta mampu menerapkan pembuatan hidroponik di rumah masing-masing walaupun pada lahan yang sempit. Hasil pengabdian masyarakat ini adalah: (1) Bertambahnya pengetahuan masyarakat akan pertanian hidroponik dengan sosialisasi melalui video campaign, dan (2) Masyarakat mengetahui cara pembuatan hidroponik pada lahan yang sempit di Desa Dalung. Kesimpulan dari adanya kegiatan pengabdian masyarakat ini adalah melalui pengenalan sistem pertanian hidroponik, masyarakat Desa Dalung maupun daerah lain di Indonesia dengan lahan sempit dapat memaksimalkan pemanfaatan lahan yang ada untuk pertanian yang produktif dan bernilai ekonomis.
\end{abstract}

Kata kunci: Hidroponik, Pertanian Lahan Sempit, Pertanian Produktif

\section{PENDAHULUAN}

Desa Dalung merupakan desa atau kelurahan yang berada di wilayah Kecamatan Kuta Utara, Kabupaten Badung, Bali yang memiliki luas wilayah 675,71 Ha, yang terdiri dari lahan permukiman, perkebunan, pertanian persawahan, kuburan, pekarangan, perkantoran, dan fasilitas umum lainnya, sebagaimana ditampilkan pada Tabel 1. 
Tabel 1. Luas Wilayah di Desa Dalung

\begin{tabular}{lc}
\hline \multicolumn{1}{c}{ Wilayah } & Luas Wilayah \\
\hline Permukiman & $256 \mathrm{Ha}$ \\
Perkebunan & $188,2 \mathrm{Ha}$ \\
Pertanian persawahan & $92,25 \mathrm{Ha}$ \\
Kuburan & $1,23 \mathrm{Ha}$ \\
Pekarangan & $41,06 \mathrm{Ha}$ \\
Perkantoran & $66,22 \mathrm{Ha}$ \\
Fasilitas umum lainnya & $30,75 \mathrm{Ha}$ \\
\hline
\end{tabular}

Jumlah masyarakat di Desa Dalung pada tahun 2017 sebesar 20.226 ribu jiwa yang tersebar dalam 5.126 ribu KK dengan total kepadatan penduduk sekitar 118 jiwa per $\mathrm{km}^{2}$. Akibat adanya kepadatan penduduk yang cukup tinggi, sehingga kebanyakan lahan dipergunakan untuk bangunan terutama untuk pemukiman penduduk. Awalnya Desa Dalung merupakan daerah yang agraris, sebagian wilayahnya adalah semak-semak, ladang serta terdiri dari tanah persawahaan yang subur dan ladang yang menghijau. Dengan kesuburan tanah tersebut, maka penduduk cukup banyak yang bermata pencaharian sebagai petani. Tetapi seiring perkembangan, rupanya sektor pertanian cenderung semakin teralihkan oleh sektor pemukiman yang semakin meningkat.

Dengan meningkatnya jumlah penduduk, hal itu berimbas terhadap kebutuhan akan hasil pertanian yang semakin meningkat pula. Oleh sebab itu, memerlukan suatu pemikiran dan solusi dalam mengatasinya, salah satu solusi yang dapat diterapkan yaitu melalui pengenalan sistem pertanian hidroponik. Hidroponik menjadi opsi yang dapat dilakukan untuk tetap menambah produktifitas pertanian terutama pada lahan yang sempit (Siswandi \& Sarwono, 2013). Hidroponik merupakan budidaya bercocok tanam dengan media tanam tanpa menggunakan tanah, melainkan seperti batu apung, kerikil, potongan kayu atau busa yang digunakan karena fungsi tanah sebagai penyokong akar tanaman serta penyalur nutrisi dapat dialihkan dengan mengalirkan atau menambah nutrisi, air dan oksigen melalui media tersebut (Roidah, 2014).

Hidroponik merupakan Bahasa Yunani yang terdiri dari "hydro" yang memiliki arti air dan "ponos" yang berarti daya atau tenaga kerja. Maka dari itu, bercocok tanam dengan sistem hidroponik merupakan cara tanam dengan menggunakan media tanam air atau tenaga kerja air. Hidroponik adalah budidaya bercocok tanam yang berbeda dari biasanya. Hidroponik memiliki arti budidaya tanaman yang memanfaatkan air dan tidak menggunakan tanah sebagai media tanamnya (soilless). Keunggulan dari teknik menanam secara hidroponik adalah tidak memerlukan lahan yang luas (Saputra et al., 2018). Kuncinya yaitu kecukupan nutrisi bagi tanaman dapat terpenuhi dan dengan bantuan sinar matahari yang memadai (Alhadi, 2016).

Hidroponik semakin banyak diketahui dan diterapkan oleh masyarakat dikarenakan oleh alasan, yakni (a) kebutuhkan konsumsi akan sayuran semakin bertambah seiring dengan bertambah pula jumlah penduduk, (b) semakin terbatasnya lahan yang dapat digunakan untuk pertanian (Yuni Lestari et al., 2019), (c) menciptakan daerah yang mandiri akan kebutuhan pangan, (d) media tanah yang sudah tercemar terutama pada daerah perkotaan saat ini, (e) efisiensi dalam pemanfaatan lahan pertanian. Hidroponik dapat diterapkan dalam lahan yang sempit dengan pendukung beberapa media tanam dan cukup mudah untuk didapatkan (Nugraha, 2019). Hal ini bertujuan untuk dapat mendukung masyarakat agar dapat bercocok tanam yang baik sehingga menjadi kebutuhan makanan sehari-hari, maka dari itu diharapkan agar masyarakat dapat memenuhi kebutuhannya dengan mudah dan juga tercukupi dengan baik. Banyak tanaman yang dapat dibudidayakan melalui sistem pertanian hidroponik, seperti pakcoi, selada, sawi, kangkung, brokoli, cabai, melon, paprika, seledri, timun, terong Jepang dan tomat (Swastika et al, 2018). Adapun keunggulan dan kelemahan sistem pertanian hidroponik (Masduki, 2018). 
Tabel 2. Keunggulan dan Kelemahan Sistem Pertanian Hidroponik

\begin{tabular}{ll}
\hline & Tanaman tidak sulit ditanam karena tanpa menyesuaikan dengan kondisi \\
& lahan pertanian dan musim \\
& Pertumbuhan serta kualitas panen tanaman dapat diatur \\
& Tidak membutuhkan tenaga kerja yang banyak dalam memelihara \\
Keunggulan & Hasil panen akan bersih dan lebih higenis \\
& Hemat dalam penggunaan air dan pupuk sehingga aman untuk kelestarian \\
& lingkungan \\
& Jangka waktu tanam lebih singkat dari pada sistem pertanian pada \\
& umumnya \\
\cline { 2 - 3 } Kelemahan & $\begin{array}{l}\text { Biaya operasional murah } \\
\text { Biaya investasi saat di awal lebih mahal } \\
\text { Sangat bergantung oleh konsentrasi dan komposisi pupuk, pH serta suhu }\end{array}$ \\
\hline
\end{tabular}

Berdasarkan penelitian sebelumnya, keterbatasan lahan bukan menjadi kendala masyarakat dalam bercocok tanam. Maka dari itu memanfaatkan lahan yang terbatas dan sempit dengan membuat tanaman hidroponik, sehingga hasil panen dari tanaman hidroponik dapat juga memenuhi gizi tubuh (Masduki, 2018). Adanya peningkatan pengetahuan serta pemahaman masyarakat mengenai sistem pertanian hidroponik dan minat masyarakat untuk bercocok tanam dengan sistem hidroponik semakin meningkat (Madusari et al., 2020). Peningkatan pengetahuan akan sistem pertanian hidroponik ini, karena pelatihan yang langsung dilakukan oleh masyarakat. Melalui pengenalan sistem pertanian hidroponik dapat meningkatkan kesadaran masyarakat untuk mengoptimalkan lahan pekarangan rumah untuk sesuatu yang produktif sehingga bernilai ekonomis (Purwasih, 2019).

Dikarenakan sistem pertanian hidroponik tidak menggunakan media tanah, maka dari itu sistem pertanian hidroponik sangat fleksibel sesuai dengan keterbatasan lahan pertanian (Nurul, 2013). Kebutuhan pangan bagi masyarakat mengalami kenaikan akibat bertambahnya jumlah penduduk. Akan tetapi tidak diseimbangi dengan kenaikan lahan pertanian, berkaitan dengan hal tersebut maka sangat penting untuk menerapkan pertanian hidroponik. Dengan mengenalkan sistem pertanian hidroponik, maka diharapkan dapat meningkatkan hasil pertanian pada lahan yang sempit dan hasil panen akan lebih cepat.

Potensi pengembangan pertanian pada skala rumah tangga di Desa Dalung sebenarnya cukup besar, sebab sebagian besar rumah penduduk memiliki halaman pekarangan yang memadai. Tujuan dilakukannya pengabdian masyarakat ini untuk mengenalkan kepada masyarakat khususnya di Desa Dalung mengenai pertanian hidroponik. Sistem pertanian hidroponik merupakan salah satu cara dalam membangun pertanian skala kecil karena dapat menyesuaikan dengan masalah lahan pertanian yang terbatas serta kemudahan proses dengan biaya yang terjangkau. Tetapi kurangnya penguasaan ilmu pengetahuan, pemanfaatan teknologi hidroponik, dan juga modal pendukung sarana dan prasarana menjadi alasan penghambat dalam penerapannya (Mulasari, 2019). Kondisi inilah yang memotivasi dilakukannya "Pengenalan Sistem Pertanian Hidroponik Rumah Tangga di Desa Dalung".

Berdasarkan permasalahan yang terdapat di Desa Dalung, adapun tujuan dari kegiatan pengabdian masyarakat, yakni:

1) Menambah pengetahuan kepada masyarakat tentang sistem pertanian hidroponik rumah tangga di Desa Dalung.

2) Mengoptimalkan lahan yang terbatas melalui sistem pertanian hidroponik di Desa Dalung. 


\section{METODE}

Kegiatan pengabdian masyarakat ini dilakukan dengan beberapa langkah untuk mencapai target luaran yang telah direncanakan, yaitu:

\subsection{Observasi Permasalahan}

Kegiatan ini bertujuan untuk mengetahui keadaan di Desa Dalung mengenai kondisi permasalahan lahan sempit yang terjadi. Kegiatan pengabdian masyarakat ini dilakukan dengan cara terlebih dahulu melakukan pengamatan dan terjun langsung ke lokasi di sekitar Desa Dalung. Setelah mengetahui kondisi permasalahan yang terjadi, maka dapat dilakukan perumusanperumusan strategi terkait dengan pelaksanaan solusi permasalahan. Selanjutnya adalah dengan menyusun secara detail rangkaian kegiatan yang akan dilakukan. Hal ini dilakukan agar dalam langkah-langkah pelaksanaan kegiatan dapat berjalan dengan lancar.

\subsection{Persiapan Alat dan Bahan}

Setelah menyusun rumusan strategi mengenai permasalahan selanjutnya persiapan alat dan bahan yang diperlukan dalam pelaksanaan kegiatan. Alat dan bahan yang telah dipersiapkan selanjutnya dijadikan sebagai penunjang dalam proses pelaksanaan kegiatan.

\subsection{Wawancara}

Pada tahap wawancara ini digunakan untuk mendapatkan data dari beberapa warga desa mengenai pengetahuan mereka tentang hidroponik. Dalam wawancara ini diajukan beberapa pertanyaan singkat mengenai hidroponik, dengan di wawancara secara langsung. Yang selanjutnya dapat diperoleh hasil berapa warga yang sudah mengetahui akan sistem pertanian hidroponik dan yang belum mengetahuinya.

\subsection{Sosialisasi Melalui Video Campaign}

Melalui tahap sosialisasi ini yang dilakukan adalah berupa pengenalan mengenai sistem pertanian hidroponik kepada masyarakat di Desa Dalung. Kegiatan sosialisasi ini dilakukan secara langsung dan melalui pembuatan video ajakan yang diposting di media sosial. Pada tahap ini, masyarakat diberikan penjelasan serta gambaran mengenai sistem pertanian hidroponik secara rinci. Hal ini berfungsi untuk mengenalkan kepada masyarakat di Desa Dalung mengenai bagaimana cara bercocok tanam tanpa menggunakan media tanah dan tanpa memerlukan lahan pertanian yang luas seperti pada umumnya. Dengan video campaign tersebut, tujuannya untuk memberikan pengetahuan tentang hidroponik serta menumbuhkan motivasi dan menunjukkan bahwa sistem pertanian hidroponik dilakukakan dengan mudah (Surtinah \& Nizar, 2017).

\subsection{Penanaman dan Pemeliharaan}

Penanaman dilakukan oleh beberapa masyarakat di Desa Dalung. Sistem budidaya serta pengamatan pertumbuhan tanaman dilakukan untuk dapat memastikan nutrisi yang terpenuhi, cahaya, pertahanan terhadap penyakit dan hama serta pengamanan terhadap hujan (Madusari et al., 2020). Langkah yang dapat diimplementasikan dalam sistem pertanian hidroponik sangat sederhana, yaitu (1) Bibit tanaman di semai pada media rockwool, (2) Bibit yang sudah disemai ditunggu waktu tumbuhnya kurang lebih satu minggu, (3) Letakkan bibit tanaman ke lubang tanam, media tanam menggunakan rockwool yang sudah diletakkan di dalam netpot dan disematkan kain flannel yang menjadi sumbu untuk menyalurkan air dan nutrisi, (4) Masukkan nutrisi sesuai takaran pada bak penampung, (5) Tunggu hingga tanaman siap untuk dipanen (Ruswaji \& Chodariyanti, 2020). 


\section{HASIL DAN PEMBAHASAN}

\subsection{Observasi Permasalahan}

Observasi permasalahan dilakukan di desa Dalung tepatnya di Banjar Kwanji pada Kamis, 28 Februari 2021 dengan juga berinteraksi kepada warga sekitar mengenai permasalahan utama yaitu lahan pertanian yang terbatas serta melakukan beberapa persiapan di tahap awal. Setelah itu dilaksanakan tinjauan lokasi untuk pembuatan hidroponik, yaitu bisa dilakukan di rumah masing-masing.

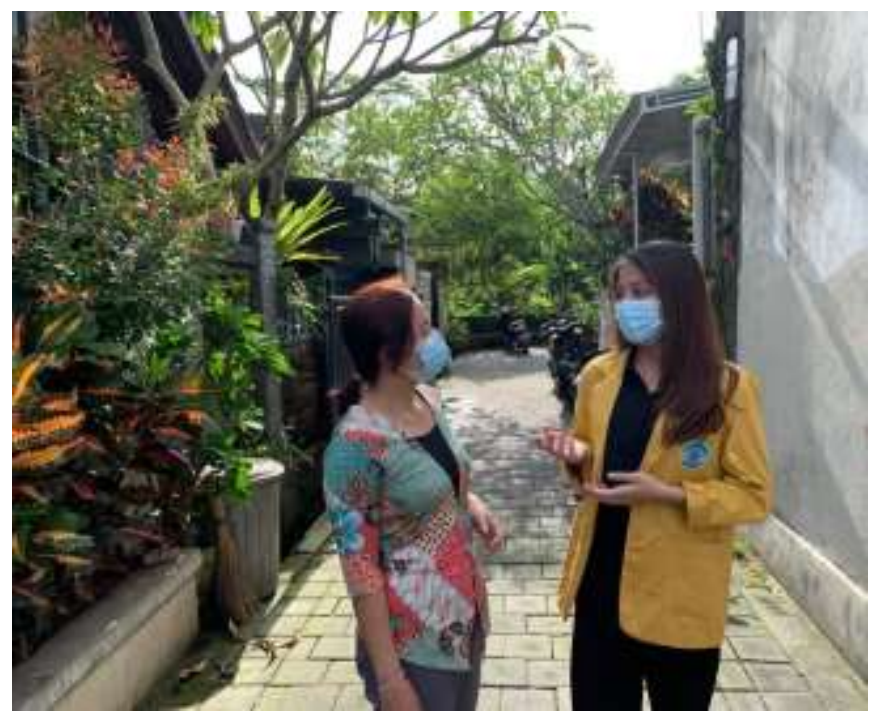

Gambar 1. Observasi Permasalahan dan Berinteraksi dengan Warga Sekitar Mengenai Permasalahan

Setelah dilakukan observasi permasalahan, maka mendapatkan hasil berupa gambaran mengenai solusi untuk permasalahan lahan yang terbatas. Kemudian menganalisis rumusan strategi yang tepat dalam menjalankan program. Selain itu juga mencari tahu lebih banyak informasi mengenai sistem pertanian hidroponik melalui sosial media, baik alat dan bahan yang diperlukan, cara pembuatan, keunggulan dan sebagainya. Kemudian langkah kegiatan disusun berdasarkan hasil observasi serta analisis, pada proses penyusunan langkah kegiatan didapatkan urutan langkah kegiatan. Sehingga didapatkan langkah-langkah kegiatan yaitu persiapan alat dan bahan, berkonsultasi dengan yang ahli dalam bidang hidroponik via online, pembuatan video campaign dan praktek langsung pembuatan pertanian hidroponik.

\subsection{Persiapan Alat dan Bahan}

Persiapan alat dan bahan untuk kebutuhan pembuatan sistem pertanian hidroponik dilaksanakan secara berangsur mulai dari tanggal 6 Februari 2021. Sebelumnya mencari tahu terlebih dahulu dimana tempat yang tepat untuk membeli alat dan bahan pembuatan hidroponik. Pembelian alat dan bahan untuk kebutuhan pembuatan sistem pertanian hidroponik yaitu di Hidroponik Bali. Adapun alat dan bahan yang dibutuhkan dalam pembuatan hidroponik diantaranya: (1) Bak dan tutup yang dilubangi, (2) Nutrisi A dan B, (3) Rockwool, (4) Benih tanaman, (5) Netpot, (6) Kain Flanel, (7) Pisau, (8) Nampan, (9) Wadah, (10) Air. 


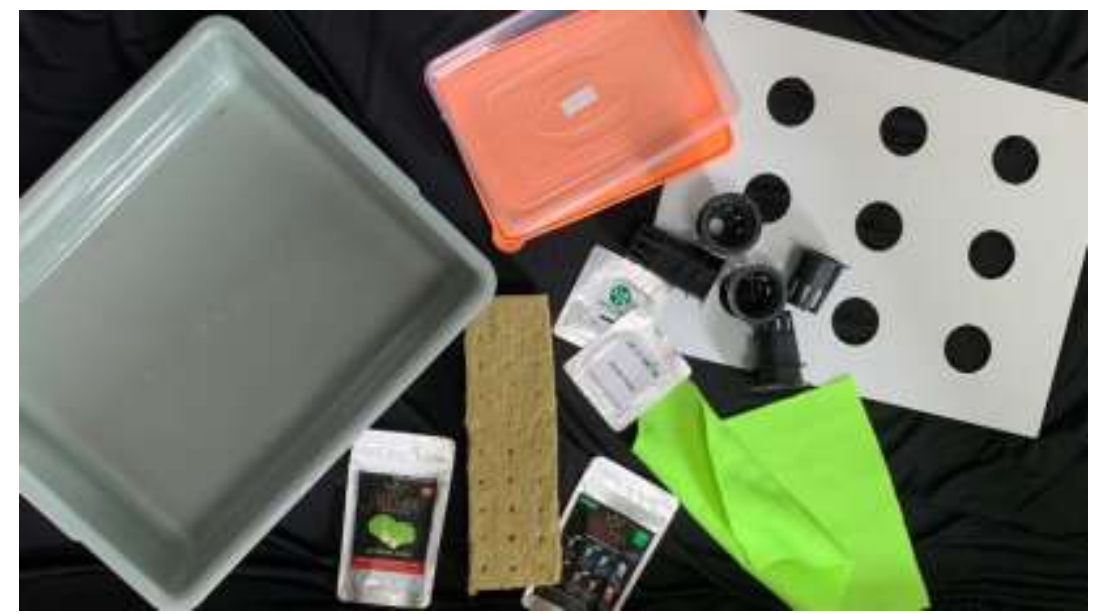

Gambar 2. Alat dan Bahan yang Dibutuhkan dalam Pembuatan Sistem Pertanian Hidroponik

\subsection{Wawancara}

Kegiatan wawancara ini dilakukan pada 9 Februari 2021, terdapat 6 orang warga yang kami ajukan pertanyaan secara langsung. Dalam wawancara ini beberapa pertanyaan yang kami ajukan, yakni, apa itu hidroponik, manfaat hidroponik, keunggulan hidroponik dan cara pembuatannya. Dari wawancara tersebut diperoleh gambaran terkait pemahaman informan terkait hidroponik, yaitu: 33\% menyatakan belum paham, 50\% paham sebagian, dan hanya 17\% sangat paham, sebagaimana dapat dilihat pada Gambar 3.

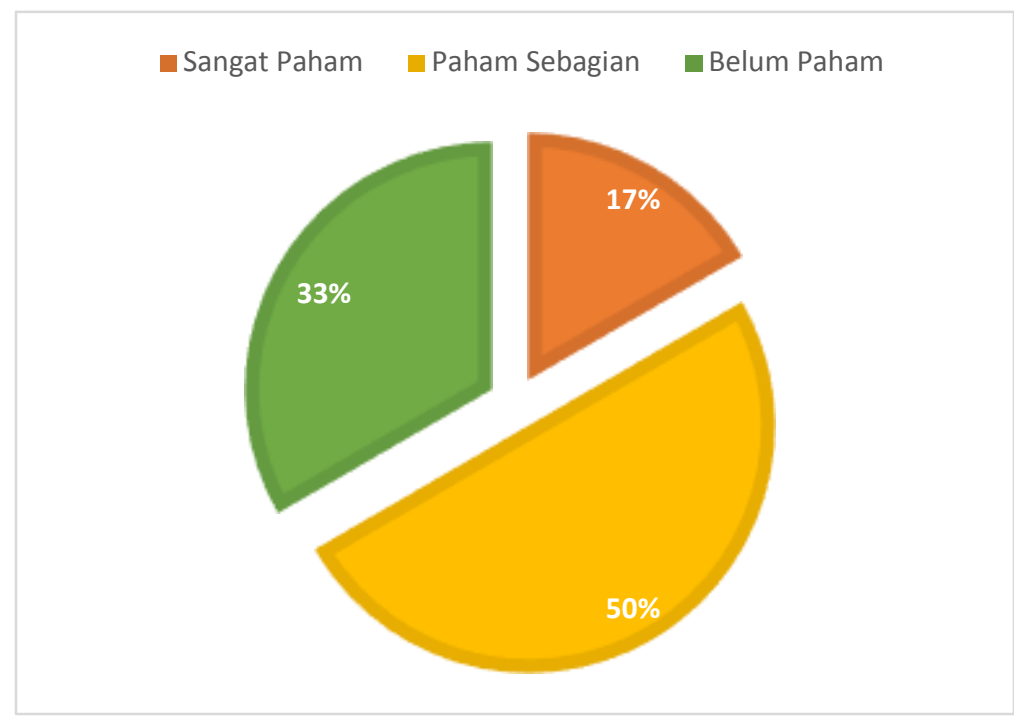

Gambar 3. Diagram Pengetahuan Warga Terkait Sistem Pertanian Hidroponik

\subsection{Sosialisasi Melalui Video Campaign}

Sebelum sosialisasi melalui video campaign, juga dilaksanakan sosialisasi secara langsung kepada warga yang hanya berjumlah 2 orang pada 15 Februari 2021. Dalam sosialisasi tersebut disampaikan manfaat hidroponik, keunggulan dan cara pembuatannya secara ringkas. Selanjutnya sosialisasi dilakukan dengan video campaign mengenai pembuatan sistem pertanian hidroponik. Video tersebut di upload pada IGTV agar masyarakat di Desa Dalung dapat melihatnya dengan mudah. Di dalam video campaign tersebut berisi tentang penjelasan mengenai hidroponik, alat dan bahan yang diperlukan, proses penyemaian benih tanaman, pembuatan nutrisi A dan B serta proses pindah tanam. Dari video campaign yang telah diposting tersebut terdapat views yang menonton video tersebut. Berikut grafik mengenai kenaikan jumlah views video campaign selama 5 hari: 


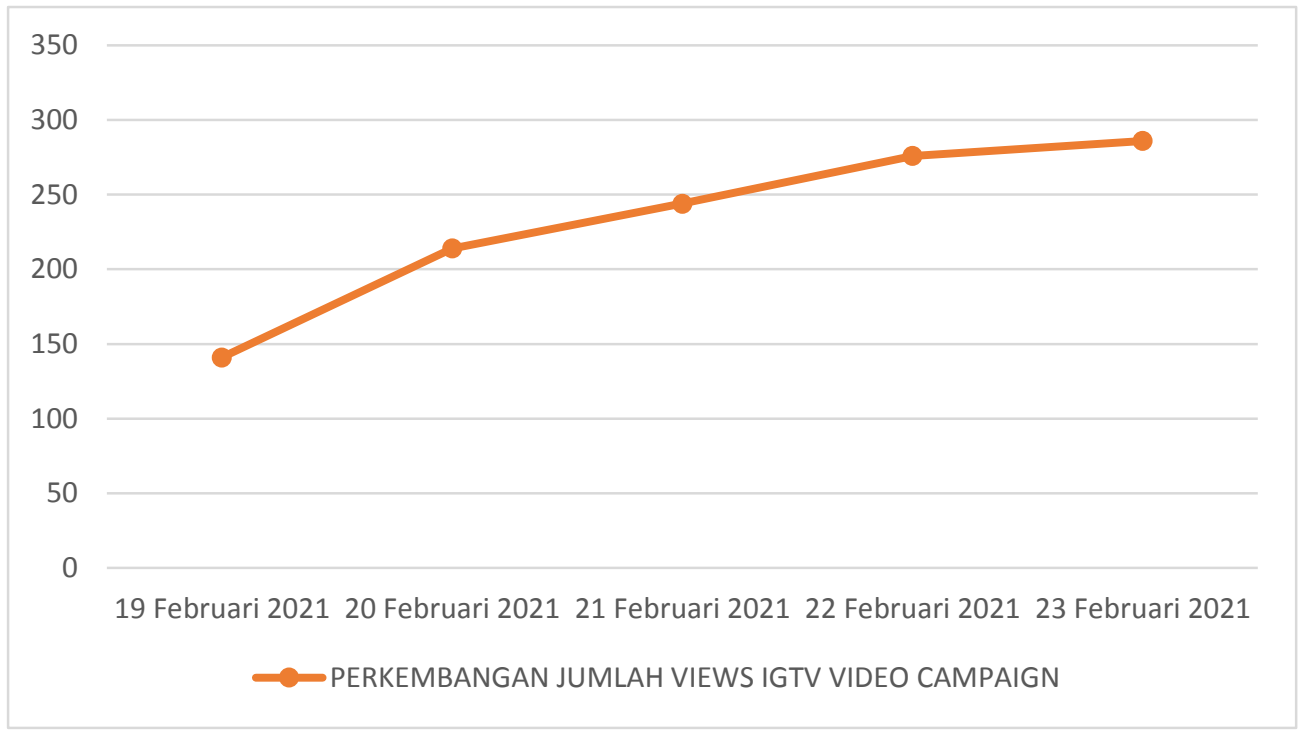

Gambar 4. Grafik Perkembangan Jumlah Views IGTV Video Campaign
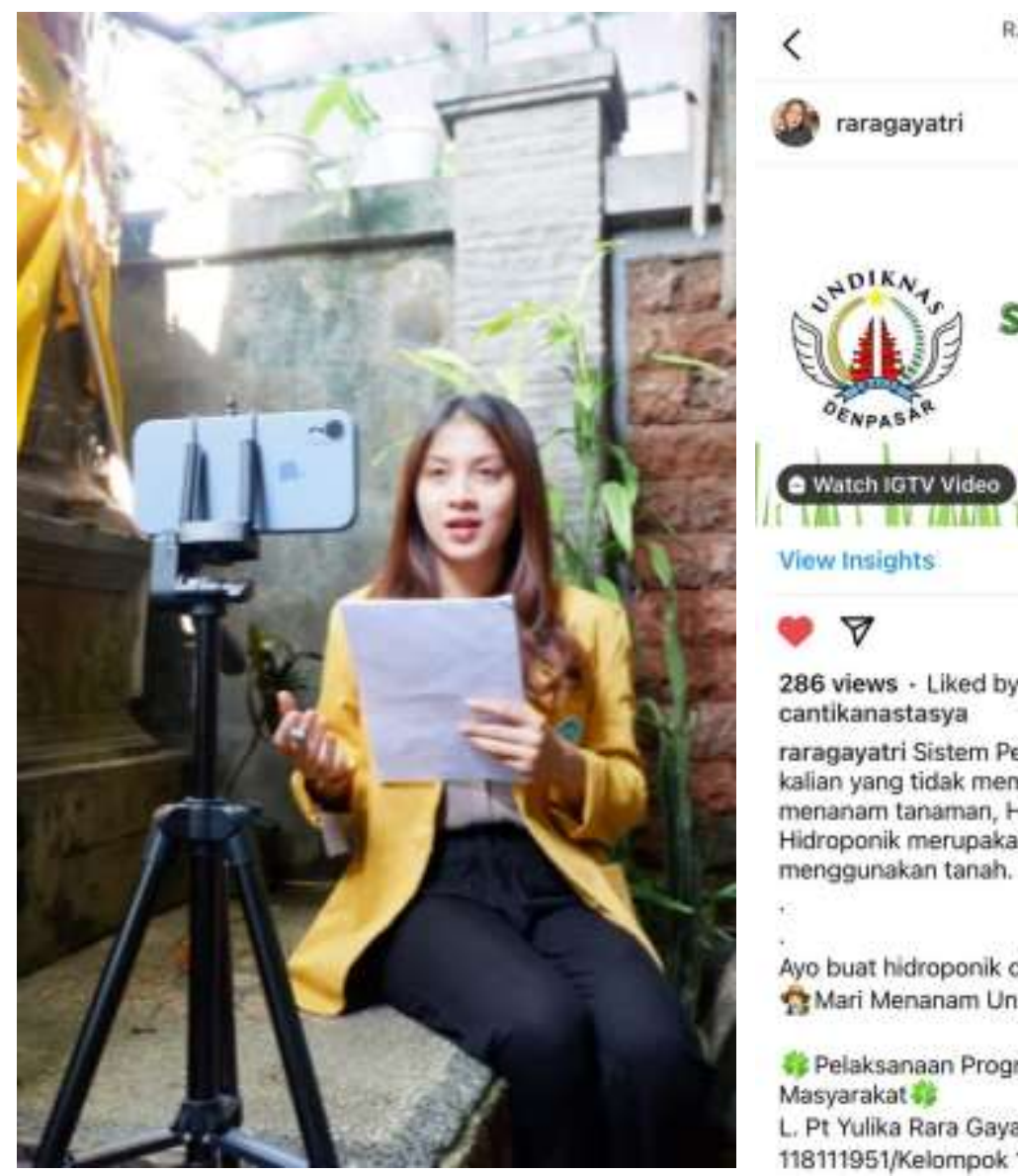

$$
\begin{aligned}
& \text { ARAGAYATRI } \\
& \text { Posts }
\end{aligned}
$$

View Insights.

\section{$\nabla$}

๑

286 views - Liked by suryanadisaputra and cantikanastasya

raragayatri Sistem Pertanian Hidroponik - OBagi kalian yang tidak memiliki banyak lahan untuk menanam tanaman, Hidroponik adalah solusinya. Hidroponik merupakan cara bercocok tanam tanpa menggunakan tanah.

Ayo buat hidroponik dirumah kalian B.Mari Menanam Untuk Masa Depan 8

4) Pelaksanaan Program Kegiatan Pengabdian Masyarakat is

L. Pt Yulika Rara Gayatri

118111951/Kelompok 17

Gambar 5. Proses Pembuatan Video Campaign dan Postingan Video Campaign 


\subsection{Penanaman dan Pemeliharaan}

Terdapat beberapa langkah spesifik dalam pembuatan tanaman hidroponik yang dilakukan pada salah satu rumah warga pada Kamis, 18 Januari 2021, yaitu:

1. Persiapkan alat dan bahan yang diperlukan.

2. Selanjutnya lakukan proses penyemaian dengan menyiapkan rockwool yang sudah dilubangi dan dibasahi serta potong rockwool menyesuaikan dengan lubang tetapi jangan sampai putus.

3. Masukkan benih pada masing-masing lubang rockwool, selanjutnya ditutup dengan plastik hitam selama 1 malam untuk mempercepat benih pecah kulit.

4. Tahap selanjutnya melarutkan nutrisi A dan B dengan air, masing-masing nutrisi dilarutkan dengan 1 liter air setelah itu ditutup rapat.

5. Isi bak dengan air lalu masukkan sedikit nutrisi A dan B, jadi 1 liter air itu berisi $10 \mathrm{ml}$ nutrisi A dan B dan diaduk sampai rata.

6. Potong kain flannel dan sematkan pada netpot untuk menyalurkan nutrisi dari bak ke rockwool.

7. Taruh benih ke dalam netpot yang sudah berisi kain flannel.

8. Lalu isikan netpot pada masing-masing lubang impraboard, pastikan kain flannel pada netpot menyentuh air nutrisi.

9. Yang terakhir letakkan tanaman di bawah sinar matahari dan tanaman siap panen kurang lebih 25 sampai 30 hari.

Serupa halnya dengan menanam, melakukan semai benih juga membutuhkan wadah serta media tanam. Tanaman juga perlu perawatan, sama halnya dengan makhluk hidup yang lainnya. Tidak hanya melakukan penyiraman tanaman setiap hari, namun juga perlu pencegahan hama penyakit. Intinya adalah sempitnya lahan pertanian bukan menjadi alasan kendala dalam bercocok tanam. Dengan demikian maka harus senantiasa bersama-sama memanfaatkan lahan yang terbatas dan sempit dengan mengembangkan tanaman hidroponik yang berguna juga dalam pemenuhan gizi tubuh (Masduki, 2018). Gambar dibawah ini merupakan cara pembuatan serta sebelum adanya pembuatan hidroponik dan sesudah adanya hidroponik.

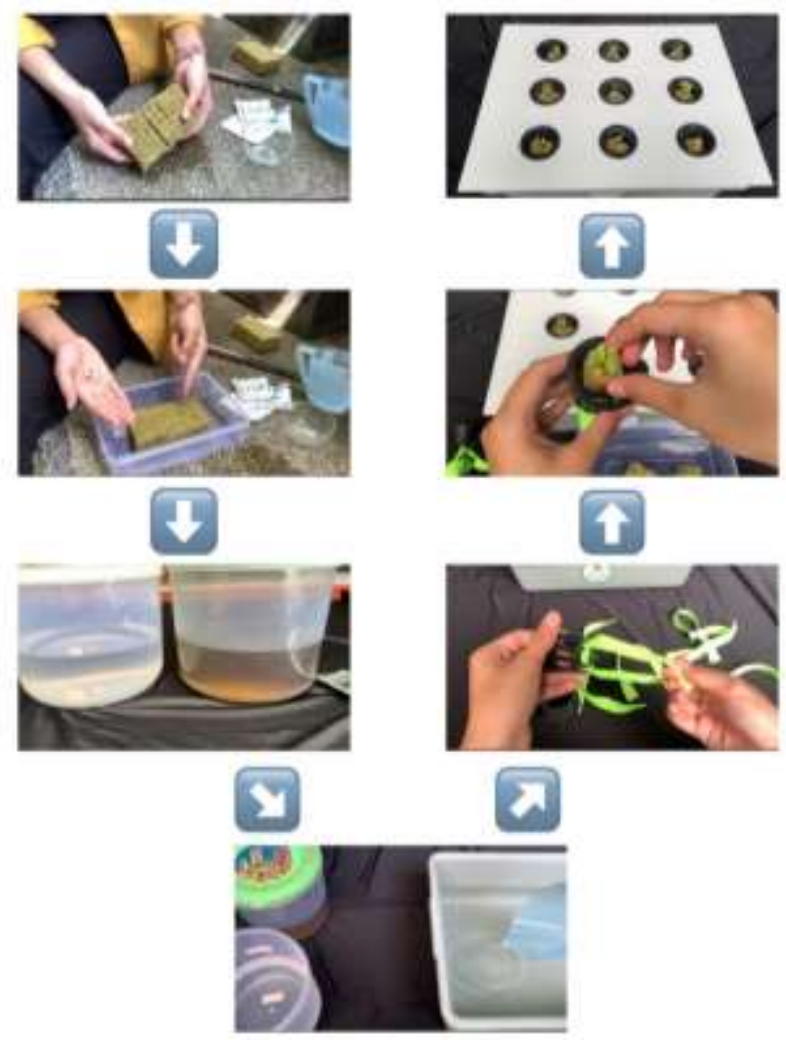

Gambar 6. Proses Pembuatan Sistem Pertanian Hidroponik 


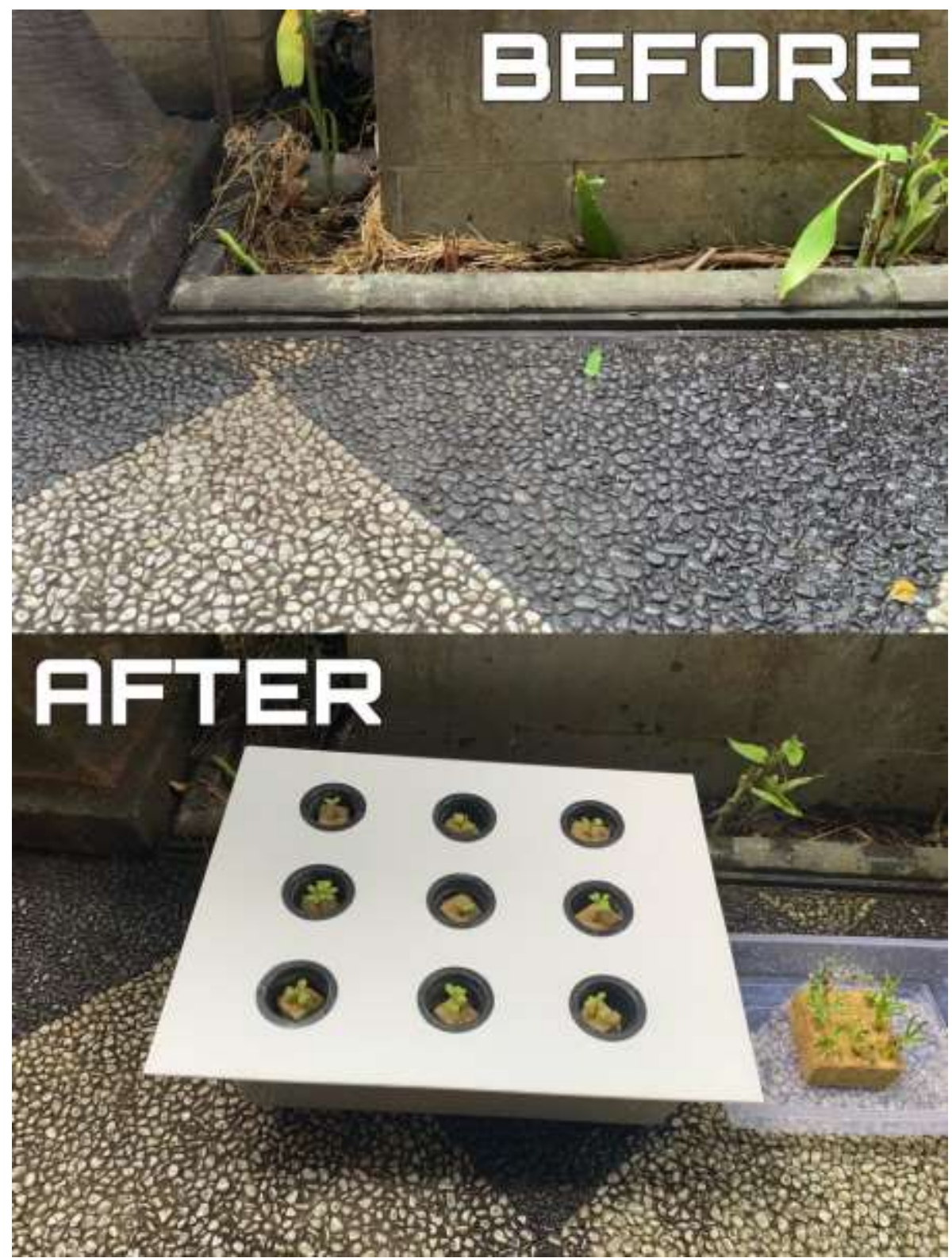

Gambar 7. Sebelum dan Sesudah Adanya Hidroponik

\section{KESIMPULAN}

Program pengabdian masyarakat di Desa Dalung ini telah berjalan dengan baik, dimulai dari tahap observasi sampai dengan sosisalisasi melalui video campaign serta penanaman. Capaian dari program pengabdian masyarakat ini adalah lebih dikenalnya sistem pertanian hidroponik dan meningkatkan pengetahuan masyarakat mengenai hidroponik. Melalui pembuatan hidroponik dapat memantapkan masyarakat utamanya dalam bidang budidaya tanaman pada lahan yang sempit atau terbatas. Harapannya pembuatan hidroponik ini menjadi salah satu alternatif yang dapat dikembangkan oleh masyarakat di Desa Dalung agar bisa bercocok tanam di pekarangan rumah dan dapat menjadi pilihan untuk menjalankan usaha.

\section{DAFTAR PUSTAKA}

Alhadi, D. (2016). Pengaruh Penggunaan Beberapa Warna Lampu Neon Terhadap Pertumbuhan Tanaman Kailan (Brassica oleraceae) Pada Sistem Hidroponik Indoor. Jurnal Teknik Pertanian Lampung (Journal of Agricultural Engineering), 5(1), 13-24. 
Madusari, S., Astutik, D., Sutopo, A., \& Handini, A. S. (2020). Ketahanan Pangan Masyarakat Pesantren. Jurnal Pengabdian Masyarakat Teknik, 2(2), 45-52. https://doi.org/10.24853/jpmt.2.2.45-52

Masduki, A. (2018). Hidroponik Sebagai Sarana Pemanfaatan Lahan Sempit Di Dusun Randubelang, Bangunharjo, Sewon, Bantul. Jurnal Pemberdayaan: Publikasi Hasil Pengabdian Kepada Masyarakat, 1(2), 185. https://doi.org/10.12928/jp.v1i2.317

Mulasari, S. A. (2019). Penerapan Teknologi Tepat Guna (Penanam Hidroponik Menggunakan Media Tanam) Bagi Masyarakat Sosrowijayan Yogyakarta. Jurnal Pemberdayaan: Publikasi Hasil Pengabdian Kepada Masyarakat, 2(3), 425. https://doi.org/10.12928/jp.v2i3.418

Nugraha, A. W. (2019). Pemberdayaan Masyarakat Desa Sumberdadi dengan Pelatihan Hidroponik dan Pupuk Organik. JPP IPTEK (Jurnal Pengabdian Dan Penerapan IPTEK), 3(1), 25-32. https://doi.org/10.31284/j.jpp-iptek.2019.v3i1.481

Nurul, mas'ud waqiah. (2013). Persepsi Masyarakat Terhadap Perawatan Ortodontik Yang Dilakukan Oleh Pihak Non Profesional, 53(9), 1689-1699.

Purwasih, R. (2019). Pemanfaatan Lahan Pekarangan untuk Budi Daya Sayuran Secara Hidroponik di Kecamatan Sungailiat, Kabupaten Bangka, Provinsi Kepulauan Bangka Belitung. Agrokreatif: Jurnal Ilmiah Pengabdian Kepada Masyarakat, 5(3), 195-201. https://doi.org/10.29244/agrokreatif.5.3.195-201

Roidah, I. S. (2014). Pemanfaatan Lahan Dengan Menggunakan Sistem Hidroponik. 1(2), 43-50.

Ruswaji, R., \& Chodariyanti, L. (2020). Pemberdayaan Masyarakat Desa Kepada Kelompok Ibu-Ibu Pkk dan Karang Taruna melalui Program Pelatihan "Hidroponik." Jurnal Abdimas Berdaya: Jurnal Pembelajaran, Pemberdayaan Dan Pengabdian Masyarakat, 2(01), 1. https://doi.org/10.30736/jab.v2i01.32

Saputra, H., Rudianto, R., Setiawan, D., \& Nugroho, R. A. (2018). Desa Wisata Hidroponik Sebagai Upaya Pemberdayaan Masyarakat Desa Sidomulyo Kecamatan Anggana Kabupaten Kutai Kartanegara. Jurnal Pengabdian Kepada Masyarakat, 24(1), 587. https://doi.org/10.24114/jpkm.v24i1.9656

Surtinah, S., \& Nizar, R. (2017). Pemanfatan Pekarangan Sempit Dengan Hidroponik Sederhana Di Pekanbaru. Jurnal Pengabdian Kepada Masyarakat, 23(2), 274. https://doi.org/10.24114/jpkm.v23i2.6876

Yuni Lestari, Ari Khusumadewi, Amang Fathurrohman, Hijrin Fitroni, \& Ubaidillah. (2019). Pemanfaatan Lahan Sempit Dengan Hidroponik Dutch Bucket System Untuk Mewujudkan Ecogreen-Pesantren Melalui Program Santripreneur Di Pondok Pesantren K.H.A. Wahid Hasyim Bangil Pasuruan. Soeropati, 2(1), 71-86. https://doi.org/10.35891/js.v2i1.1778 